Errata

\title{
Human erythrocyte superoxide dismutase activity during deep diving
}

\section{J. A. Paciorek}

Chemistry Department, Bergen University, Allégt 41, N-5000 Bergen, Norway

Eur J Appl Physiol (1985) 54:163-171

The enzyme classification should read 1.15.1.1., not 1.15.11. Also, in Fig. 3. The horizontal axis should be 1.0 bar, not 0.1 bar.

\section{Creatine kinase and creatine kinase $\mathrm{MB}$ in endurance runners and in patients with myocardial infarction}

\author{
M. Stäubli ${ }^{1}$, B. Roessler ${ }^{1}$, H. P. Köchli ${ }^{2}$, E. Peheim ${ }^{2}$, and P. W. Straub ${ }^{1}$ \\ Departments of Internal Medicine ${ }^{1}$ and of Clinical Chemistry ${ }^{2}$, University of Berne, Switzerland \\ Eur J Appl Physiol (1985) 54:40_45
}

The sentence beginning on line 18 of the Introduction should read as follows:

In only one study has the time course of CK and CKMB after long distance running been de- scribed (Apple et al. 1984) and it has been found that the half time of disappearance of $\mathrm{CK}$ and CKMB is longer in runners than in patients. 